\title{
Extension Decision Under Conditions of Oligopoly
}

\author{
Huangfu Liu ${ }^{1, *}$ Bo Liu ${ }^{2}$
}

\author{
${ }^{1}$ IPSOS Group, Beijing 100020, China \\ ${ }^{2}$ School of Mathematics \& Quantitative Economics, Shandong University of Finance and Economics, Jinan, \\ Shandong 250014, China \\ *Corresponding author. Email: zmbpp@126.com
}

\begin{abstract}
Following the extension theory, this paper investigates the decisions of oligopoly. The results of this paper show that the matter-element transformation is the effective tool by which the oligopolies construct the set of strategy, and the extension theory can be applied to the decision of oligopoly and develop the theory of oligopoly.
\end{abstract}

Keywords: The extension theory, Extension decision, Matter-element transformation, Oligopoly.

\section{INTRODUCTION}

Nobel Prize-winning economist Stigler (1987) argues that, though most economists have discussed oligopoly pricing and market strategy since the 1840 s, this research field remains a controversial area in economics. In an oligopoly industry, if one firm changes its product price or alters another part of its marketing strategy, it significantly impacts the rival firm(s). So there is much uncertainty in the decisions of oligopoly firms. Economists have developed dozens of special models applying to special cases, but none of those deal with the behavior of oligopolists in general. In contrast to the existing literature, this article, based on the extension theory contributed by Cai (1983), establishes a matter-element model of oligopoly, and presents a new method to make oligopoly decisions.

\section{THE EXTENSION THEORY}

The extension theory studies contradictory problems where goals and conditions are contradictory. To solve contradictory problems, Wen Cai contributed several key concepts around 1983.

\subsection{Matter-element}

In the real world, the quantitative change and qualitative change of one thing are closely interrelated and interact with each other. Classical mathematics considers only the quantities and forms of objects, so it has limitations in dealing with qualitative change. Now the extension theory can be used to describe the thinking process associated with both quantitative change and qualitative change.

Matter-element, which is the logic cell of the extension theory, is an ordered triad $\mathrm{R}=(\mathrm{N}, \mathrm{c}, \mathrm{v})$ where $N$ denotes the matter; $c$ is the characteristics; $v$ is $N$ 's measure about $c$; the expression $v=c(N)$ describes the relationship between quality and quantity. If a matter has many characteristicelements, it can be described by n-dimensional matter-elements:

$R=\left(\begin{array}{ccc}N, & c_{1}, & v_{1} \\ & c_{2} & v_{2} \\ \cdots & \cdots \\ & c_{n} & v_{n}\end{array}\right)$

\subsection{Extensibility of Things}

Extensibility of things is the possibility for opening up things. It is necessary to open up things in order to solve contradictory problems. And the opening-up carried out is called extension.

The extensibility of things can be described by extensibility of matter-element, including the divergent nature, the conjugate nature, the correlative nature, the implicative nature and the expansive nature (Cai,1994). 


\subsection{Matter-element Transformations}

The transformation which turns $R_{0}=\left(N_{0}, c_{0}, v_{0}\right)$ into another matter-element $R=(N, c, v)$ or into several matter-elements $R_{1}=\left(N_{1}, c_{1}, v_{1}\right), \ldots, R_{\mathrm{n}}=$ $\left(N_{\mathrm{n}}, c_{\mathrm{n}}, v_{\mathrm{n}}\right)$, is called the transformation of $R_{0}$.

Replacement, decomposition, increasing (or decreasing), and expansion (or contraction) are the four basic transformations of matter-elements. Matter-element transformations possess four basic operations, namely: and, or, product, and negation (Cai, 1994).

The extensibility of matter-element points out possible way to solve problems, and matter-element transformations and their combinations can describe the ideas and strategies. Therefore the extension theory can formalize activities of creative thinking, such as knowledge innovation, new product design and strategy generation. It will now be applied to the decisions of oligopoly.

\section{PROBLEM AND MATTER- ELEMENT MODEL}

A problem is defined as realizing the designated goals by designated conditions. Goals and conditions of a problem can be denoted by matterelements, which are separately called goal matterelements and condition matter-elements. In one oligopoly industry, for simplicity, two companies are considered. A further assumption is that the number of products sold is $\mathrm{Q}$, the price of the product is $\mathrm{P}$, and each company attempts to maximize profits.

The goal matter-elements of the oligopoly problem can be written as:

$R=R_{1} \otimes R_{2}$

$R_{1}=\left(\right.$ Firm 1, profit,$\left.\pi_{1}\right)$

$R_{2}=\left(\right.$ Firm 2, profit, $\left.\pi_{2}\right)$

The condition matter-elements are written as:

$r=r_{1} \otimes r_{2} \otimes r_{3}$

$r_{1}=\left(\begin{array}{ccc}\text { Consumers }, & \text { price, } & P \\ & \text { demand, } & Q\end{array}\right)$

$r_{2}=\left(\right.$ Firm $\left.1, \quad \cos t, C_{1}\right)$

$r_{3}=\left(\right.$ Firm $\left.2, \cos t, C_{2}\right)$

Thus the matter-element model can represent the oligopoly problem:

$$
R * r=\left(R_{1} \otimes R_{2}\right) *\left(r_{1} \otimes r_{2} \otimes r_{3}\right)
$$

If both firms want to monopolize the market, matter-element $R_{1}$ and $R_{2}$ are in opposing positions, i.e. $R_{1} \uparrow R_{2}$, so the above problem becomes an opposing problem, $\left(R_{1} \uparrow R_{2}\right)^{*} r$. This strategy sometimes leads to unwanted results, such as low prices and zero economic profits in an oligopoly. But the oligopolists can consider the possibility of a cooperative solution with monopoly prices and profits. Therefore the opposing problem $\left(R_{1} \uparrow R_{2}\right) * r$ can be changed to a compatible problem. Moreover, this change can be obtained by goal matter-element transformations, condition matter-element transformations, or both transformations simultaneously.

\section{THE SOLUTION OF THE PROBLEM}

In order to solve the oligopoly problem, we will get a series of strategies through transformations of goal matter-elements or condition matter-elements. And those strategies can be comprehensively appraised by classical methods.

\subsection{Transformations of Matter-elements}

The transformations of matters, characteristics and measures possess four basic transformations, namely: replacement, decomposition, increasing (or decreasing), and expansion (or contraction). From the results of the transformations, good ones are chosen as follows.

- Transformations of goal matter-element $\mathrm{R}_{1}$

a) $\mathrm{TR}_{11}$ : According to the difference of products, Firm 1 can be divided into several parts.

b) $\mathrm{TR}_{12}$ : The two firms can be allied.

c) $\mathrm{TR}_{13}$ : The characteristic profit can be changed into sale volume.

- Transformations of goal matter-element $\mathrm{R}_{2}$

a) $\mathrm{TR}_{21}$ : According to the difference of products, Firm 2 can be divided into several parts.

b) $\mathrm{TR}_{22}$ : The two firms can be allied.

c) $\mathrm{TR}_{23}$ : The characteristic profit can be changed into sale volume.

- Transformations of condition matterelement $r_{1}$

a) $\operatorname{Tr}_{11}$ : The number of consumers can be increased by developing the potential goods market.

b) $\operatorname{Tr}_{12}$ : Consumers can be separated into several groups through market analysis, according to the difference of products. 
- Transformations of condition matterelement $r_{2}$

a) $\operatorname{Tr}_{21}$ : According to the difference of products, Firm 1 can be divided into several parts.

b) $\operatorname{Tr}_{22}$ : The two firms can be allied.

c) $\operatorname{Tr}_{23}$ : The cost of Firm 1 can be decreased.

- Transformations of condition matterelement $r_{3}$

a) $\operatorname{Tr}_{31}$ : According to the difference of products, Firm 2 can be divided into several parts.

b) $\operatorname{Tr}_{32}$ : The two firms can be allied.

c) $\operatorname{Tr}_{33}$ : The cost of Firm 2 can be decreased.

\subsection{Available Transformations}

$\mathrm{TR}_{11}, \mathrm{TR}_{12}, \mathrm{TR}_{13}, \mathrm{TR}_{21}, \mathrm{TR}_{22}, \mathrm{TR}_{23}, \mathrm{Tr}_{11}, \mathrm{Tr}_{12}$, $\mathrm{Tr}_{21}, \mathrm{Tr}_{22}, \mathrm{Tr}_{23}, \mathrm{Tr}_{31}, \mathrm{Tr}_{32}$ and $\operatorname{Tr}_{33}$ are combined into the basic transformations of the problem, and composed into a large transformation set. Then these transformations are evaluated according to the goals of firms, and three available transformations are chosen.

$$
\left(T R_{11} \otimes T R_{21}\right) *\left(T r_{12} \otimes T r_{23} \otimes T r_{33}\right)
$$

Based on the product differentiation, each firm can serve niches or pockets of demand through market segmentation. For example, the automobile market can be categorized as both a truck market and a car market. If Firm 1 specializes in the production of trucks and Firm 2 in the production of cars, Firm 1 should exit from the car market and produce trucks, while Firm 2 should exit from the truck market and produce cars in order to take advantage of important economies of scale in production. With few varieties and styles, more specialized and faster machinery can be developed for a continuous operation and a longer production run. Each firm can specialize in the production of only a few varieties and styles of a product, and unit costs fall sharply.

This strategy, which has not been involved in oligopoly theory, means the extension theory can be applied to the decisions of oligopoly and can develop the theory of oligopoly.

$$
\left(T R_{12} \otimes T R_{22}\right) * e(2)
$$

The two firms can, in principle, get together, agree on a common strategy, and share out the gains from it among themselves. When firms collude and behave in a monopoly-like fashion, they will be able to restrict output and charge a higher price. Each firm will see its profits increase in the short run as companies engage in price setting and cooperate to keep out competitors. Collusion and cartels are not legal in the United States, but fairly common in other countries.

$$
\left(T R_{13} \otimes T R_{23}\right) * e
$$

The firm can change its objective from maximizing profits to maximizing sales. Businessmen are not always concerned with maximizing profits or minimizing costs; they sometimes attempt to achieve a greater share of existing product sales in existing markets. This can be done by expansion, in essence taking share from existing competitors, or by taking over or acquiring all or part of a competing business. Growth is a prime goal for most firms and businesses. But the product life-cycle curve shows that it is relatively easy to grow during the "growth" stage, although increasing market share may not be so easy, and that growth and share increases are much more difficult to achieve in the maturity and decline stages.

\section{CONCLUSION}

In the above content, there is a large transformation set, in which the strategies appearing or not appearing in the oligopoly theory can be chosen and (1), (2) and (3) are the special cases. Furthermore, (1) and (2) conform to the thought of transforming the bridge method, which is also one of the extension engineering methods. So both the extension decision method and the transforming bridge method can be applied into oligopoly decision, and the extension theory is a powerful tool for oligopoly decision. Whether or not other extension engineering methods can be applied into oligopoly decision needs to be studied further.

\section{AUTHORS' CONTRIBUTIONS}

Huangfu Liu designed the study, performed the research, and wrote the paper. Bo Liu contributed to the conception of the study, conducted the analysis and wrote the paper.

\section{REFERENCES}

[1] W. Cai, "The extension set and noncompatible problem, Science Exploration," in Chinese, Vol.3, No.1 pp. 83-97, 1983. 
[2] W. Cai, Matter-element models and their application, in Chinese, Beijing: Science and Technology Documentation Publishers, 1994.

[3] Stigler, G., The theory of price, MacMillan Publishing Company, 1987.

[4] H. Zhu, Y. Ding, H. Cha, S. Li, "Analysis and Improvement of Decision Trees with Extension Logic and Extension Thinking Mode," Journal of Guangdong University of Technology, Vol. 36, No.2, March, 2019.

[5] L. Xu, X. Li, Y. Guo, "Nonlinear extension dependent degree method to three-parameter interval number decision making," Control and Decision, Vol.34, No.10, Oct. 2019.

[6] H. Liu, X. Geng, "Performance Evaluation of Public Sector Based on Extension Evaluation Method: Applicability, Main Steps and Applications," Journal of Systems Science, Vol. 28, No. 1, Feb. 2020. 